\title{
Evaluation of primary care responsiveness by people with mental illness in Spain
}

\author{
Valle Coronado-Vázquez 1,2,3,4,5, María Josefa Gil-de-Gómez 1,6, Eva Rodríguez-Eguizábal 1,7, \\ Bárbara Oliván-Blázquez ${ }^{4,5,8}$, Juan Gómez-Salgado ${ }^{9,10^{*}}$, Rosa Magallón-Botaya ${ }^{4,5,8,11}$ and \\ María Antonia Sánchez-Calavera ${ }^{4,5,8,12}$
}

\begin{abstract}
Background: The health system responsiveness is a concept developed by the World Health Organization that measures patients' expectations for the non-medical care they receive. The aim of this study is to assess primary care responsiveness as seen by people with mental illness and to analyse the factors associated with poor responsiveness.

Methods: Cross-sectional descriptive study on 426 people with mental illness who had attended primary care consultations at least once in the previous 12 months. The responsiveness of the health system was determined through the short questionnaire "Multi-country Survey Study on Health and Health Systems Responsiveness". Differences in responsiveness by sociodemographic characteristics were compared through the Chi-squared test. Logistic regression identified the factors associated with poor responsiveness.

Results: Overall responsiveness was measured as good by $77.4 \%$ of patients, being this probability higher in the domains: dignity, confidentiality, and communication. The most valued domains by people with mental illness were prompt attention (42.4\%), dignity (30.1\%), and communication (17\%). Only prompt attention scored high importance and poor responsiveness. In patients with an income lower than 900 euros per month and low level of studies, the probability of poor confidentiality responsiveness was multiplied by 3 and 2.7 respectively.

Conclusions: People with mental illness perceive good responsiveness from primary care in terms of dignity, confidentiality, and communication. Prompt attention, as the domain of greatest importance and worst valuation, should be prioritised through the implementation of organisational measures in health centres to reduce waiting times, especially in urban areas.
\end{abstract}

Keywords: Responsiveness, Primary care, Mental illness

\section{Background}

The assessment of responsiveness is now considered a key objective by health systems [1]. The concept was developed by the World Health Organization to assess the response to legitimate patient expectations for nonmedical aspects of health care [2]. This includes people's

\footnotetext{
*Correspondence: jgsalgad@gmail.com

${ }^{10}$ Safety and Health Postgraduate Programme, Universidad Espíritu Santo, 092301 Guayaquil, Ecuador

Full list of author information is available at the end of the article
}

expectations of how they should be treated and in what environments and, on the other hand, people's experiences when interacting with the health system regarding participation processes [3]. In this sense, Valentine et al. established three levels of responsiveness: the context where services are provided, users and providers that define the need for attention, and the individual care process [4].

On the other hand, Mirzoev et al. determined a conceptual framework in which people's interactions and experiences are the basic components of the health 
system, so clarifying these expectations can help respond to people's needs [5].

Unlike patient satisfaction, mainly focused on the clinical care received, responsiveness is oriented to the health system as a whole. It is expected that, if patient expectations are met, satisfaction with the received care, which has been related to both therapeutic compliance and clinical outcomes [6], will improve.

Primary care can be defined as "the provision of integrated and accessible health care services by clinicians who are accountable for addressing a large majority of personal health care needs, developing a sustained partnership with patients and practicing in the context of family and community" [7]. One of the main characteristics of primary care is universality and accessibility, facilitating continuity and coordination of care, and becoming the health service with more patients cared for [8]. Studies on the responsiveness of primary care have generally focused on specific population groups, as in the case of those developed by Kerssens et al. on a sample of fragile patients [9]. In other cases, research has been aimed at comparing public with private services, as well as urban services with rural ones [10].

A study on primary care in different European countries concluded that responsiveness is associated with the type of link the physician has with the health system and with health expenditure, so patients cared for by paid physicians via capitation positively value the attention received, and in countries with higher expenditure on health, a better assessment of the dignity and autonomy domains is recorded $[11,12]$. In Spain, with mixed remuneration (salary and capitation), responsiveness was valued as poor [11].

With regard to mental health, the prevalence of mental disorders in the Spanish adult population has been estimated at $10.7 \%$ [13]. People with mental health problems frequently interact with primary care services. Thus, up to $58.8 \%$ of the health problems addressed in family medicine consultations correspond to mental illnesses, being anxiety (46.7\%) and depression (41.7\%) the most common [14]. These reach $47 \%$ in people over the age of 75 , who are commonly associated with other comorbidities [15].

In Spain, a community model of care has been followed for people with mental health problems with the aim of providing comprehensive care, focusing on prevention and following the principles of accessibility, continuity, autonomy, and equity. That is why community mental health professionals work in a coordinated and interdisciplinary manner with primary care teams [16]. The Spanish mental health system is composed of a specialized and integrative network that supports primary care, and which is made up of salaried professionals and residential and intermediate centres in the community, where there are multidisciplinary clinical teams that provide services. In primary care, it is general practitioners who care for patients, establishing treatment or referring them to a specialized network. In recent years, some elements such as person-centered care, population-based improvements, user experience, and a look to the costs and care of the professional have been added to this model of community mental health. Progress has also been made in the development of assessment models, although a future national mental health strategy should incorporate the participation of patients and their families [17].

In addition, the stigma associated with mental illness and its treatment makes these patients more vulnerable and discourages individuals from getting proper mental health treatment [18]. So it is interesting to know their perception of primary care responsiveness and its associated factors in order to adapt the care provided to the needs of patients.

The objective of this study was to evaluate the responsiveness of the health system in primary care, both globally and for each of the domains, as valued by people with mental illness, with or without other chronic diseases, and to identify socioeconomic variables associated with poor responsiveness.

\section{Methods}

Cross-sectional descriptive study through the use of a validated questionnaire.

All methods were carried out in accordance with relevant guidelines (STROBE) and regulations (COPE, ICMJE).

The study population consisted of patients over the age of 18, with at least one mental illness (no specific type of mental illness was included), in pharmacological and/or psychological treatment who, for any reason, had attended primary care consultations of the public health system in any of two Spanish regions (Aragon and La Rioja) in the 12 months prior to the start of the study. Aragon and La Rioja are two regions of northern Spain, which have a population density of 27.8 inhabitants $/ \mathrm{Km} 2$ and 63.4 inhabitants $/ \mathrm{Km} 2$ respectively.

Other inclusion criteria were not having cognitive impairment or receiving palliative care. To confirm the absence of cognitive impairment, the Mini-Mental State Examination was performed.

Consecutive sampling was performed for all patients meeting the inclusion criteria. The sample size was calculated considering that the proportion of patients reporting good responsiveness is a maximum of 53\% [19]. With an accuracy of $5 \%$ and a $95 \%$ confidence interval, it was determined that 383 people should be included. Rating 
an expected $10 \%$ dropout rate, 426 people (213 from each region) had to be recruited.

Sources for data collection were the electronic medical history and interviews with the patients. Data were collected for all factors that could influence the assessment of the health system responsiveness, such as socioeconomic variables, self-perceived health status, and place of residence. The state of self-perceived health refers to the sociodemographic question: "Generally speaking, how would you describe your current state of health?". This answer could range from Very good/good, normal, bad/ very bad.

As an outcome variable, the assessment of the responsiveness of the global health system and for each of the domains was considered (see Supplemental Digital Content 1). To this end, the WHO "Multi-country Survey Study on Health and Health Systems Responsiveness (MCSS)" was used, which has been developed in 61 countries and validated in Spanish [19]. Seven of the eight domains (dignity, confidentiality, communication, autonomy, prompt attention, quality of basic amenities, and choice of provider) were considered, as the social consideration domain is only valued in patients admitted to hospital. These domains were measured on a Likert scale with five categories (very poor, poor, moderate, good, and very good), which were grouped for their analysis into "good" responsiveness (combining "good" and "very good") and "poor" responsiveness (with "moderate", "poor", and "very poor" responses combined) (see Supplemental Digital Content 1). In addition, participants valued which domain was the most important to them.

Data were collected from July 2018 to December 2019 through 30 -min interviews conducted by eight trained surveyors. Family physicians invited patients who met the inclusion criteria to participate in the survey. Those who accepted the invitation were referred to an interviewer who provided them with information about the characteristics and duration of the questionnaire and requested consent to participate in the study. Individual, structured interviews were conducted.

A pilot study was conducted to detect and address reliability issues in the data collection notebook.

The statistical analysis was performed with the SPSS software (Statistical Package for Social Sciences) V.24.0 (IBM SPSS). After cleaning up data, quantitative and qualitative variables were analysed using numerical and graphical statistics. To compare sociodemographic variables and responsiveness, contingency tables were made, and the Chi-squared test was used. OR and 95\% confidence interval (95\% CI) were calculated. A logistic regression model determined the association between geographic area and responsiveness, controlling the confounding variables.

\section{Ethical considerations}

This protocol was approved by the Aragon Research Ethics Committee (Zaragoza, Spain), with number code PI17/194. All participants signed an informed consent prior to conducting the interviews.

\section{Results}

\section{Characteristics of the participants}

Four hundred twenty-nine people with mental illness were interviewed. $78.8 \%(n=338)$ were women and $21.2 \%(n=91)$ were men. The mean age was 62 years (CI 95\%: 60.5-63.6). A 68\% of the participants belonged to the region of Aragon, the $41.5 \%$ resided in a city of more than 50,000 inhabitants, and $38.9 \%$ had a bad or very bad state of self-perceived health.

In $80.7 \%$ of patients, there was an associated chronic disease: $35.4 \%$ had high blood pressure, $13.3 \%$ were diabetic, and $13.5 \%$ had a rheumatological disease.

The sample characteristics according to the presence/ absence of chronic disease are presented in Table 1.

\section{Use of medical health services}

In the 30 days prior to the interview, $81.6 \%$ of patients had visited the family physician and 37.5\% had visited the community nurse. When they needed prompt attention, $45.7 \%$ said they had always obtained it.

The mean age of family physicians was 51.6 years $(\mathrm{SD}=0.28)$ and $78.8 \%$ were women.

\section{Health system objectives}

$63.3 \%$ of participants believed that the most important goal of the health system was to improve health for all; for $61.1 \%$, the second in importance was improving the treatment of people when receiving health care; and for $85.3 \%$ of the participants, the least important objective was that of the economic contribution that each must make to sustain the health system

\section{Primary care responsiveness}

Overall responsiveness was good for $77.4 \%$ of patients (CI 95\%: 73.2-81.1), being this probability higher in the domains: dignity 96.7\% (CI 95\%: 94.6-98), confidentiality 94.7\% (CI 95\%: 92.1-96.5), and communication 94.2\% (CI 95\%: 91.5-96).

Responsiveness was poor most often in the domains: autonomy $12.7 \%$ (CI 95\%: 9.7-16.2), choice 13.2\% (CI 95\%: 9.9-17 4), prompt attention 25.8\% (CI 95\%: $21.8-$ 30.2 ), and quality of basic amenities $50.9 \%$ (CI 95\%: 46.2-55.6). 
Table 1 Sociodemographic characteristics according to the presence of a chronic illness

\begin{tabular}{|c|c|c|c|}
\hline & $\begin{array}{l}\text { Patients with mental illness } n(\%) \\
n=83\end{array}$ & $\begin{array}{l}\text { Patients with mental illness and other chronic } \\
\text { illness } n(\%) n=346\end{array}$ & p \\
\hline Sex & & & 0.63 \\
\hline Male & $16(19.3)$ & $75(21.7)$ & \\
\hline Age (years) & & & 0.001 \\
\hline$<60$ & $66(81.5)$ & $127(38)$ & \\
\hline$\geq 60$ & $15(18.5)$ & $207(62)$ & \\
\hline Marital status & & & 0.001 \\
\hline Single & $18(19.3)$ & $42(12.1)$ & \\
\hline Separate & $13(15.7)$ & $27(7.8)$ & \\
\hline Married/living as a couple & $51(61.4)$ & $200(57.8)$ & \\
\hline Widow/er & $3(3.6)$ & $77(22.3)$ & \\
\hline Level of studies & & & 0.001 \\
\hline Basic & $19(22.9)$ & $197(56.9)$ & \\
\hline Intermediate & $50(60.2)$ & $117(36.7)$ & \\
\hline High & $14(16.9)$ & $22(6.4)$ & \\
\hline Area of residence & & & 0.07 \\
\hline$<10.000$ Inhab. & $35(42.2)$ & $102(29.5)$ & \\
\hline 10.000 a 50.000 Inhab. & $17(20.5)$ & $97(28)$ & \\
\hline$>50.000$ Inhab. & $31(37.3)$ & $147(42.5)$ & \\
\hline Occupation & & & 0.001 \\
\hline Employed & $23(27.7)$ & $53(15.3)$ & \\
\hline Unemployed & $29(34.9)$ & $77(22.3)$ & \\
\hline Retiree/Disabled & $31(37.3)$ & $216(62.4)$ & \\
\hline Social status & & & 0.14 \\
\hline Low & $40(49.4)$ & $132(40.5)$ & \\
\hline Intermediate-high & $41(55.6)$ & $194(59.5)$ & \\
\hline Level of income & & & 0.005 \\
\hline$<900 € /$ month & $5(7.5)$ & $73(25.8)$ & \\
\hline$\geq 900 € /$ month & $62(92.5)$ & $210(74.2)$ & \\
\hline Type of psychiatric illness & & & 0.32 \\
\hline Schizoaffective disorder & $4(4.8)$ & $11(3.2)$ & \\
\hline Depressive disorder & $28(37.7)$ & $147(42.5)$ & \\
\hline Anxiety disorder & $39(47)$ & $130(37.6)$ & \\
\hline Other & $12(14.5)$ & $58(16.8)$ & \\
\hline Duration of psychiatric illness & & & 0.05 \\
\hline More than 10years & $21(31.8)$ & $129(44.6)$ & \\
\hline Less than or 10 years & $45(68.2)$ & $160(55.4)$ & \\
\hline Private insurance & & & 0.27 \\
\hline Yes & $13(15.7)$ & $34(9.8)$ & \\
\hline Attending to family physician & & & 0.90 \\
\hline Never & $12(14.5)$ & $50(14.5)$ & \\
\hline 1 to 4 times & $67(80.7)$ & $283(81.8)$ & \\
\hline More than 4 times & $4(4.8)$ & $13(3.8)$ & \\
\hline Attending to PC nursing & & & 0.03 \\
\hline Never & $59(71.1)$ & $193(55.8)$ & \\
\hline 1 to 4 times & $21(25.3)$ & $140(40.5)$ & \\
\hline More than 4 times & $3(3.6)$ & $13(3.8)$ & \\
\hline Attending to psychologist & & & 0.04 \\
\hline Never & $71(85.5)$ & $323(93.4)$ & \\
\hline 1 to 4 times & $12(14.5)$ & $22(6.4)$ & \\
\hline
\end{tabular}


Table 1 (continued)

\begin{tabular}{lll}
\hline & $\begin{array}{l}\text { Patients with mental illness } \mathbf{n}(\%) \\
\boldsymbol{n = 8 3}\end{array}$ & $\begin{array}{l}\text { Patients with mental illness and other chronic } \\
\text { illness } \mathbf{n}(\%) \boldsymbol{n}=\mathbf{3 4 6}\end{array}$ \\
\hline $\begin{array}{l}\text { More than 4 times } \\
\begin{array}{l}\text { Health state } \\
\text { Good/Nery good }\end{array}\end{array}$ & $1(0)$ & \\
Normal & $26(31.3)$ & $74(21.4)$ \\
Bad/Nery bad & $32(38.6)$ & $130(37.6)$ \\
\hline
\end{tabular}

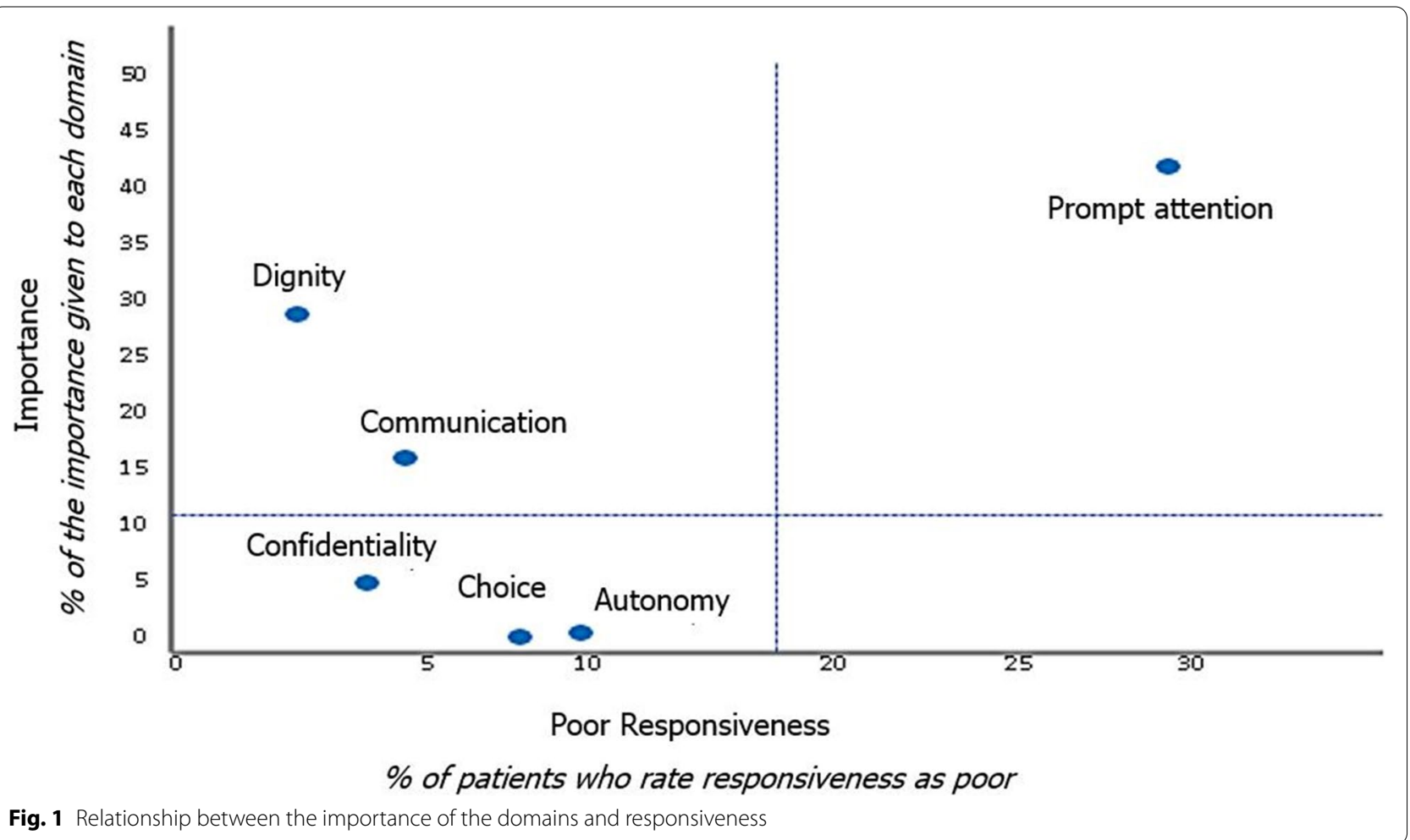

$57.8 \%$ of patients who experienced poor responsiveness regarding prompt attention also showed poor overall responsiveness $(p<0.005)$

The most valued domains by people with mental illness were prompt attention (42.4\%), dignity (30.1\%), and communication (17\%), but only prompt attention scored high in importance and poor in responsiveness (Fig. 1).

Choice (10.7\%) was the domain that was given the lowest value, along with autonomy (8.9\%) and confidentiality (3.3\%).

\section{Responsiveness, social status, and educational level}

In $19.4 \%$ of patients with an income below 900 euros per month, responsiveness was poor for the autonomy domain, as compared to $11.3 \%(p=0.06)$, and for $10.5 \%$ of them, confidentiality was poor versus $3.8 \%$ of them $(p=0.02)$. Among these, for those with an income of 900 or more euros per month, the probability of rating responsiveness as poor regarding confidentiality was multiplied by 3 (OR=3; CI 95\%: 1.1-7.8).

$7.6 \%$ of those with a low level of studies showed poor responsiveness in confidentiality, as compared to $2.9 \%(p=0.03)$, and $19.6 \%$ valued prompt attention as poor versus $32.2 \%$ ( $p=0.003$ ) (Table 2$)$. Compared to those with a high level of studies, the likelihood of rating responsiveness as poor in confidentiality terms was multiplied by 2.7 (95\% CI: $1.1-7.2$ ) and by 0.5 (CI 95\%: $0.3-0.8$ ) as regards prompt attention (Table 3 ) 
Table 2 Proportion of responsiveness according to socioeconomic level, level of studies, and place of residence

\begin{tabular}{lllll}
\hline Poor responsiveness & $\begin{array}{l}\text { Social status } \\
\text { (Low) }\end{array}$ & $\begin{array}{l}\text { Economic income } \\
(<900 \text { euros/month) }\end{array}$ & $\begin{array}{l}\text { Level of studies } \\
\text { (Low) }\end{array}$ & $\begin{array}{l}\text { Size of place } \\
\text { of residence } \\
(>\mathbf{5 0 . 0 0 0} \\
\text { inhab.) }\end{array}$ \\
\hline Global & & & 21.8 & 24.7 \\
Dignity & 22.7 & 25.6 & 3.2 & 4.5 \\
Confidentiality & 4.1 & 2.6 & $7.6^{*}$ & 3.9 \\
Communication & 6.5 & $10.5^{*}$ & 6.5 & 5.1 \\
Autonomy & 6.4 & 7.7 & 13.2 & 14 \\
Choice & 14.5 & 19.4 & 15.3 & 10.7 \\
Prompt attention & 15 & 10.3 & $19.6^{*}$ & $38.8^{*}$ \\
Quality of amenities & 26.7 & 22.4 & 52.3 & 56.2 \\
\hline
\end{tabular}

${ }^{*} p<0.05$

Table 3 Association between responsiveness and Sociodemographic variables. Logistic regression

\begin{tabular}{llllll}
\hline & $\begin{array}{l}\text { Place of residence } \\
\text { Ref: }<50.000 \text { Inhab. } \\
\text { OR (CI 95\%) }\end{array}$ & $\begin{array}{l}\text { Social status } \\
\text { Ref: Intermediate-high } \\
\text { OR (CI 95\%) }\end{array}$ & $\begin{array}{l}\text { Economic income } \\
\text { Ref: } \geq \text { 900 Euros } \\
\text { OR (Cl 95\%) }\end{array}$ & $\begin{array}{l}\text { Level of studies } \\
\text { Ref: intermediate-high } \\
\text { OR (CI 95\%) }\end{array}$ & $\begin{array}{l}\text { Illness evolution } \\
\text { Ref: } \leq \text { 10years } \\
\text { OR (Cl 95\%) }\end{array}$ \\
\hline Global & $1.2(0.8-1.9)$ & $1(0.6-1.6)$ & $1.4(0.8-2.4)$ & $0.9(0.5-1.4)$ & $0.9(0.6-1.6)$ \\
Dignity & $1.9(0.7-5.6)$ & $1.6(0.5-1.9)$ & $0.9(0.2-2.2)$ & $0.9(0.3-2.8)$ & $0.8(0.3-2.6)$ \\
Confidentiality & $0.29(0.24-1.53)$ & $1.5(0.6-3.6)$ & $3(1.1-7.8)^{*}$ & $2.7(1.1-7.2)^{*}$ & $1.3(0.6-3.4)$ \\
Communication & $0.78(0.34-1.8)$ & $1.1(0.5-2.6)$ & $2.2(0.8-6.2)$ & $1.2(0.5-2.8)$ & $1.2(0.5-2.9)$ \\
Autonomy & $1.2(0.7-2.2)$ & $1.3(0.7-2.3)$ & $1.9(0.9-3.8)$ & $1.1(0.6-1.9)$ & $1.3(0.7-2.5)$ \\
Choice & $0.62(0.32-1.2)$ & $1.2(0.6-2.4)$ & $0.8(0.3-2.1)$ & $1.4(0.7-2.8)$ & $2.6(1.2-5.4)^{*}$ \\
Prompt attention & $3(1.9-4.8)^{*}$ & $1.5(0.8-1.8)$ & $0.9(0.6-1.5)$ & $0.5(0.3-0.8)^{*}$ & $1.4(0.9-2.3)$ \\
Cleanliness & $2(1.3-3.1)^{*}$ & $0.5(0.3-0.9)^{*}$ & $1.2(0.7-2.1)$ & $0.7(0.5-1.1)$ & $0.8(0.5-1.3)$ \\
Amenities & $1.8(1.2-2.7)^{*}$ & $0.7(0.5-1.2)$ & $1.4(0.8-2.4)$ & $0.8(0.5-1.2)$ & $0.8(0.5-1.2)$ \\
Quality of services & $1.4(0.9-2.1)$ & $1.2(0.8-1.7)$ & $1.2(0.7-2.1)$ & $1.1(0.7-1.6)$ & $0.7(0.4-1)$
\end{tabular}

${ }^{*} p<0.05$

\section{Responsiveness and health status}

The presence of other chronic diseases was related to good responsiveness in all domains, except for the quality of basic amenities, where $51.9 \%$ rated it as poor, though the differences were not significant.

People with mental illness and other chronic disease most importantly valued the domains of prompt attention (41.5\%), dignity (32.8\%), and communication (17.6\%), albeit without statistical significance (Fig. 2).

An association was found between the health state and some domains. Among those who perceived their health state as bad or very bad, $35.8 \%$ rated responsiveness regarding prompt attention as poor, as also $5.4 \%$ as regards the dignity domain $(p<0.05)$.

In patients with a mental illness of more than 10 years of evolution, the likelihood of valuing responsiveness as poor in the choice domain was multiplied by 2.6 (Table 3).
The number of visits to the family physician was also related to some domains. $34.4 \%$ of patients who had attended the consultation between once and four times in the previous month scored poor when it came to cleanliness ( $\mathrm{p}-0.009)$, and $11.5 \%$ in the choice domain $(p=0.04)$.

\section{Responsiveness and environment}

$38.8 \%$ of patients living in areas larger than 50,000 people valued responsiveness as poor in the prompt attention domain, versus $17.3 \%(p<0.05)$. There were no significant differences for the other domains

Among these patients, for those residing in areas of less than 50,000 inhabitants, the likelihood of scoring responsiveness as poor was multiplied by 3 as regards prompt attention, by 2 when it came to cleanliness, and by 1.8 regarding basic amenities $(p<0.05)$. 


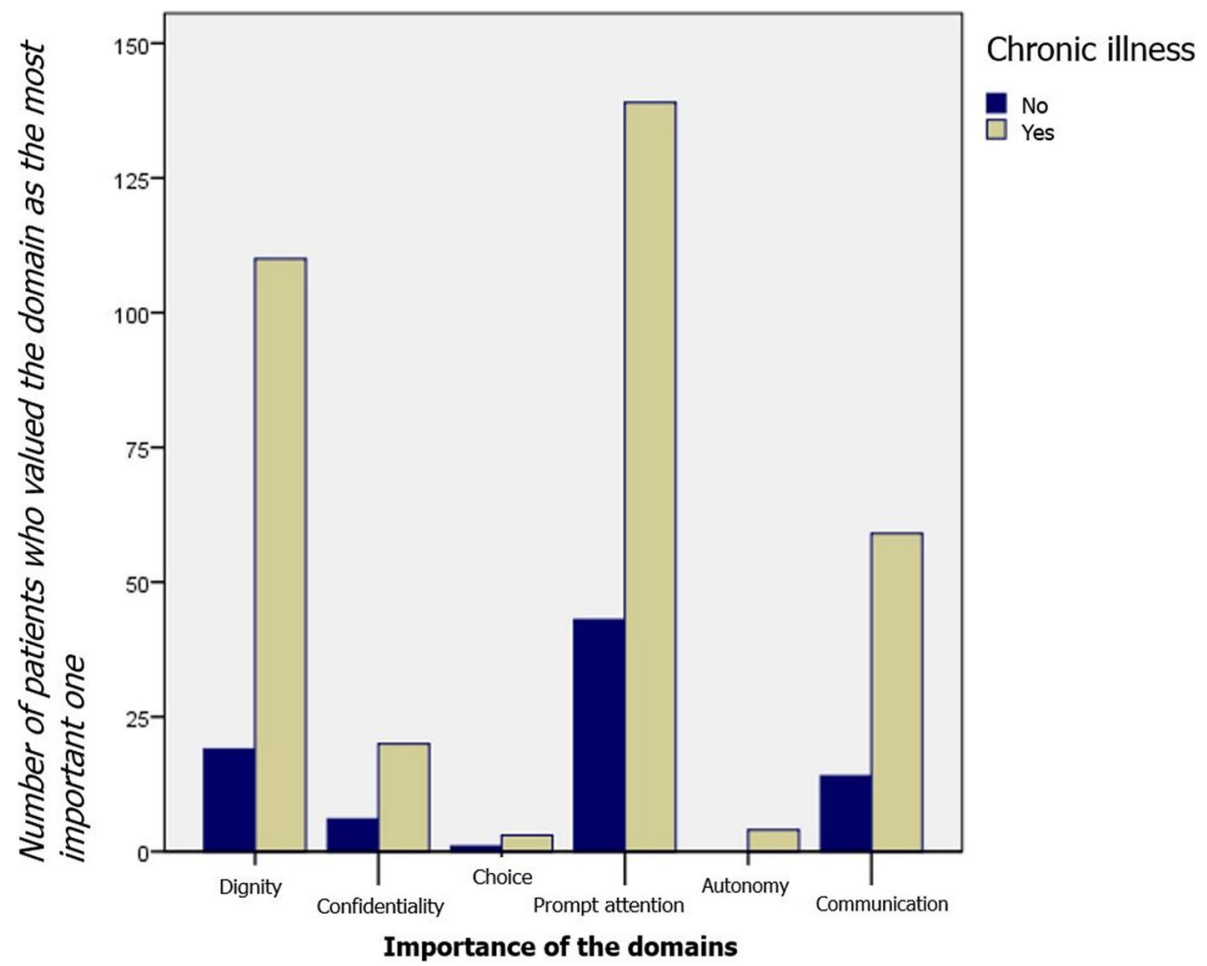

Fig. 2 Representation of the importance of the domains according to the presence of chronic illness

In the multiple regression performed, the relationship between an income lower than 900 euros per month and poor responsiveness in confidentiality did not change when adjusting the size of the place of residence.

\section{Discussion}

This study has assessed primary care responsiveness as valued by people with mental illness in two Spanish regions, and the factors associated with poor responsiveness.

For most patients, overall responsiveness was good, the highest percentages corresponding to domains that indicate respect for people: dignity, confidentiality, and communication.

Dignity was the domain most often valued as good, implying that people with mental illness perceive respectful treatment without stigmatisation from primary care professionals. Confidentiality was the second in frequency, indicating that patients are confident in that information about their disease will be maintained private. These findings are also described in studies conducted on people with mental illness outside the scope of primary care $[20,21]$. Confidentiality relates to the preservation of personal data, and this is an important aspect in these patients as, when this is not guaranteed, there may be a refusal to share the information [22]. In the present study, most of the participants valued this dimension as good by generally indicating a high degree of trust in the family physicians who assist them.

Often, responsiveness was rated as poor in the autonomy domain and in those dealing with the provision of services such as choice, prompt attention, and quality of basic amenities. Other studies find similar results, as in Iran's mental health services [20], where prompt attention, quality of basic amenities, and autonomy were the domains with the worst valued responsiveness, or in Germany [21], where this was the case for the quality of basic amenities and autonomy domains.

It has been suggested that some changes in the interaction between healthcare professionals and patients, such as maintaining an empathetic relationship, may serve as a tool to increase their experience of participation and thus promote their autonomy [23]. People with mental illness want more active participation in treatments and service planning [24], therefore primary care is an optimal location for mental health services because of the possibilities for continuity of care and therapeutic relationships, which is of utmost importance to patients [25]. That is why promoting certain behaviours from institutions and the professionals working in them could contribute to reducing overprotecting attitudes in treating these patients. 
The perception of poor responsiveness in prompt attention can be explained by the increased demand for primary care that also increases the time to be assisted, as suggested by Liu et al. [26] in their study. In addition, this is the domain that scored highest in importance and poor responsiveness.

Unlike Bramenfeld et al.s [21] findings in outpatient care for patients with mental illness, where autonomy and prompt attention were considered the most important domains, in the present study, these domains are prompt attention, dignity, and communication.

In patients with a poor health state, responsiveness was valued as poor in the domains of prompt attention and dignity. Unlike this, in Forouzan et al's study, experience with dignity in mentally ill patients who had been hospitalised was poor for those with a good health state [20].

It has been found that responsiveness is related to the duration of the mental illness, so it is poor in the choice domain for patients with a disease of more than 10 years of evolution. This can be explained because, over time, the ability to choose new services is reduced. However, in Bramesfeld's study al [21]., those who had long suffered the disease perceived responsiveness as good, which is attributed to the reduction in expectations of these patients.

For patients with an income lower than 900 euros $(€)$ per month, responsiveness was poor in the autonomy and confidentiality domains, and also in confidentiality for those with a low level of studies. However, among these, the likelihood that the responsiveness in prompt attention was poor was reduced by half. These findings are consistent with those from other studies [21].

Institutions should include the necessary actions to improve care in the mental health plans of people with fewer economic resources and a low level of education. Thus, Aragon's mental health strategy, being one of the regions where the study has been carried out, includes procedures and resources to ensure access to services and continuity of care [27].

Unlike the Gabrani J. et al's [10] study, responsiveness in prompt attention was worse valued in urban areas. To try to alleviate this situation, measures such as improving times organisation and an adequate allocation of tasks among primary care professionals, as well as carrying out patient health education interventions [28], should be implemented.

In the present study, only 7 of the 8 responsiveness dimensions defined by WHO were used, as one of them was not applicable to primary care services. Possible information biases have been minimised through questionnaire piloting and surveyors' training.

\section{Conclusions}

People with mental illness perceive good responsiveness of the primary care system in terms of dignity, confidentiality, and communication. Prompt attention should be prioritised as the domain of greatest importance and worst valuation through the implementation of organisational measures in health centres to reduce waiting times, especially in urban areas.

It is necessary to give patients more participation opportunities in decision-making and provide confidence in the guarantee of privacy of their personal data, mainly in those with fewer economic resources and low educational level.

\section{Abbreviations}

WHO: World Health Organization; MCSS: Multi-country Survey Study on Health and Health Systems Responsiveness; SPSS: Statistical Package for Social Sciences; OR: Odds Ratio; Cl: Confidence Interval; SD: Standard Deviation.

\section{Supplementary Information}

The online version contains supplementary material available at https://doi. org/10.1186/s12913-022-07516-2.

Additional file 1: Supplemental Digital Content 1. Definition of the domains $(\mathrm{WHO})$

\section{Acknowledgements}

We wish to thank the Primary Care Prevention and Health Promotion Network (redIAPP-Carlos III Health Institute, Spain). Also, the Primary Health Care Research Group of Aragon (GAIAPB21-20R) of the Department of Science, University and Knowledge of the Government of Aragon (Spain) along with Feder Funds "Another way to make Europe".

\section{Authors' contributions}

Valle Coronado-Vázquez: Conceptualization; Data curation; Formal analysis; Investigation; Methodology; Project administration; Resources; Software; Supervision; Validation; Visualization; Roles/Writing - original draft; Writing review \& editing. Maria Josefa Gil-de-Gómez: Conceptualization; Data curation; Formal analysis; Investigation; Methodology; Project administration; Resources; Software; Supervision; Validation; Visualization; Roles/Writing - original draft; Writing - review \& editing. Eva Rodríguez-Eguizábal: Conceptualization; Data curation; Formal analysis; Investigation; Methodology; Resources; Software; Supervision; Validation; Visualization; Roles/Writing - original draft; Writing review \& editing. Bárbara Oliván-Blázquez: Conceptualization; Data curation; Formal analysis; Investigation; Methodology; Project administration; Resources; Software; Supervision; Validation; Visualization; Roles/Writing - original draft; Writing - review \& editing. Juan Gómez-Salgado: Conceptualization; Data curation; Formal analysis; Funding acquisition; Investigation; Methodology; Resources; Software; Supervision; Validation; Visualization; Roles/Writing - original draft; Writing - review \& editing. Rosa Magallón-Botaya: Conceptualization; Data curation; Formal analysis; Investigation; Methodology; Project administration; Resources; Software; Supervision; Validation; Visualization; Roles/Writing - original draft; Writing - review \& editing. María Antonia Sánchez-Calavera: Conceptualization; Data curation; Formal analysis; Investigation; Methodology; Project administration; Resources; Software; Supervision; Validation; Visualization; Roles/Writing - original draft; Writing - review \& editing. The authors read and approved the final manuscript.

\section{Funding}

This work was supported by the Instituto Aragonés de Ciencias de la Salud (grant number PI17/02274). 


\section{Availability of data and materials}

The dataset supporting the conclusions of this article is included within the article (and its additional file).

\section{Declarations}

Ethics approval and consent to participate

This protocol was approved by the Aragon Research Ethics Committee (Zaragoza, Spain), with number code PI17/194. All participants signed an informed consent prior to conducting the interviews.

\section{Consent for publication}

Not applicable.

\section{Competing interests}

None declared.

\begin{abstract}
Author details
${ }^{1}$ Aragonese Institute for Health Sciences (IACS), 50009 Zaragoza, Spain. ${ }^{2}$ School of Medicine, Universidad Francisco de Vitoria, 28223 Madrid, Spain. ${ }^{3}$ Illescas Primary Care Health Center, Castilla-La Mancha Health Service, 45200 Toledo, Spain. ${ }^{4}$ Group B21-20R, Health Research Institute of Aragon (IIS), 50009 Zaragoza, Spain. ${ }^{5}$ redlAPP group RD16/0007/0005, Aragonese Primary Care Research Group, 50009 Zaragoza, Spain. ${ }^{6}$ San Pedro Hospital, La Rioja Health Service, 26006 Logroño, Spain. ${ }^{7}$ Puerta de Arnedo Primary Care Health Center, La Rioja Health Service, 26580 Arnedo, Spain. ${ }^{8}$ University of Zaragoza, 50009 Zaragoza, Spain. ${ }^{9}$ Department of Sociology, Social Work and Public Health. Campus El Carmen, Universidad de Huelva, Av. de 3 de Marzo, 21007 Huelva, Spain. ${ }^{10}$ Safety and Health Postgraduate Programme, Universidad Espíritu Santo, 092301 Guayaquil, Ecuador. ${ }^{11}$ Arrabal Primary Care Health Center, Aragon Health Service, 50009 Zaragoza, Spain. ${ }^{12}$ Fuentes Norte Primary Care Health Center, Aragon Health Service, 50002 Zaragoza, Spain.
\end{abstract}

Received: 22 June 2021 Accepted: 17 January 2022

Published online: 31 January 2022

\section{References}

1. World Health Organization (WHO). Everybody business: strengthening health systems to improve health outcomes: WHO's framework for action. Geneva: World Health Organization; 2007.

2. World Health Organization (WHO). The world health report 2000. Health systems: improving performance. Geneva: World Health Organization; 2000.

3. De Silva A. A framework for measuring responsiveness. GPE discussion paper series $N^{\circ}$ 32. Geneva: World Health Organization; 2000.

4. Valentine N, Prasad A, Rice N, Robone S, Smith P. Health systems responsiveness - a measure of the acceptability of health care processes and systems. In: Mossialos E, et al., editors. Performance measurement for health system improvement: experiences, challenges and prospects. London: WHO European Regional Office; 2008.

5. Mirzoev T, Kane S. What is health systems responsiveness? Review of existing knowledge and proposed conceptual framework. BMJ Glob Health. 2017;2(4):e000486. https://doi.org/10.1136/bmjgh-2017-000486.

6. Alazri MH, Neal RD. The association between satisfaction with services provided in primary care and outcomes in type 2 diabetes mellitus. Diabet Med. 2003 Jun;20(6):486-90.

7. Vanselow NA, Donaldson MS, Yordy KD. A new definition of primary care. JAMA. 1995;273(3):192.

8. Starfield B. Politics, primary healthcare and health: was Virchow right? J Epidemiol Community Health. 2011;65(8):653-5.

9. Kerssens JJ, Groenewegen PP, Sixma HJ, Boerma WG, van der Eijk I. Comparison of patient evaluations of health care quality in relation to WHO measures of achievement in 12 European countries. Bull World Health Organ. 2004;82(2):106-14 Available at: https://www.ncbi.nlm.nih.gov/pmc/ articles/PMC2585905/pdf/15042232.pdf.

10. Gabrani J, Schindler C, Wyss K. Perspectives of public and private primary healthcare users in two regions of Albania on non-clinical quality of care. J Prim Care Community Health. 2020;11:2150132720970350. https://doi.org/ $10.1177 / 2150132720970350$
11. Murante AM, Seghieri C, Vainieri M, Schäfer WLA. Patient-perceived responsiveness of primary care systems across Europe and the relationship with the health expenditure and remuneration systems of primary care doctors. Soc Sci Med. 2017 Aug; 186:139-47.

12. Kringos DS, Boerma WG, Hutchinson A, van der Zee J, Groenewegen PP. The breadth of primary care: a systematic literature review of its core dimensions. BMC Health Serv Res. 2010;10:65.

13. De Pedro CJ, Saiz Ruiz J, Roca M, Noguer I. Salud mental y salud pública en España: vigilancia epidemiológica y prevención. Rev Psiquiatr Salud Ment. 2016;23:67-73.

14. Doherty S, Hulland E, Lopes-Cardozo B, Kirupakaran S, Surenthirakumaran $\mathrm{R}$, Cookson S, et al. Prevalence of mental disorders and epidemiological associations in post-conflict primary care attendees: a cross-sectional study in the Northern Province of Sri Lanka. BMC Psychiatry. 2019;19(1):83.

15. Robone S, Rice N, Smith PC. Health systems'responsiveness and its characteristics: a cross-country comparative analysis. Health Serv Res. 2011;46(6pt2):2079-100.

16. Juliá-Sanchis R, Aguilera-Serrano C, Megías-Lizancos F, Martínez-Riera JR. Evolución y estado del Modelo comunitario de atención a la salud mental. Informe SESPAS 2020 [evolution and status of the community model of mental health care. SESPAS report 2020]. Gac Sanit. 2020;34 Suppl 1:81-6 Spanish.

17. Holder SM, Peterson ER, Stephens R, Crandall LA. Stigma in mental health at the macro and micro levels: implications for mental health consumers and professionals. Community Ment Health J. 2018;55(3):369-74.

18. Salvador-Carulla L, Almeda N, Álvarez-Gálvez J, García-Alonso C. En la montaña rusa: breve historia del Modelo de atención de salud mental en España. Informe SESPAS 2020 [on the roller coaster: an abridged history of mental health planning in Spain. SESPAS report 2020]. Gac Sanit. 2020;34 Suppl 1:3-10 Spanish.

19. World Health Organization (WHO). Plan de acción sobre Salud mental 2013-2020. Geneva:World Health Organization. Available at: http:/apps.who.int/iris/bitst ream/10665/97488/1/9789243506029_spa.pdf?ua=1. Accessed 12 Dec 2021.

20. Forouzan S, Padyab M, Rafiey H, Ghazinour M, Dejman M, San SM. Measuring the mental health-care system responsiveness: results of an outpatient survey in Tehran. Front Public Health. 2016:3:285.

21. Bramesfeld A, Wedegärtner F, Elgeti H, Bisson S. How does mental health care perform in respect to service users' expectations? Evaluating inpatient and outpatient care in Germany with the WHO responsiveness concept. BMC Health Serv Res. 2007;7:99.

22. Blignault I, Ponzio V, Rong Y, Eisenbruch M. A qualitative study of barriers to mental health services utilisation among migrants from mainland China in south-East Sydney. Int J Soc Psychiatry. 2008 Mar;54(2):180-90.

23. Grant VJ, Briscoe J. Everyday ethics in an acute psychiatric unit. J Med Ethics. 2002;28(3):173-6. https://doi.org/10.1136/jme.28.3.173.

24. Glenister D. Patient participation in psychiatric services: a literature review and proposal for a research strategy. J Adv Nurs. 1994;19(4):802-11.

25. Ashcroft R, Menear M, Greenblatt A, Silveira J, Dahrouge S, et al. Patient perspectives on quality of care for depression and anxiety in primary health care teams: a qualitative study. Health Expect. 2021;24(4):1168-77. https:// doi.org/10.1111/hex.13242.

26. Liu Q, Zhou W, Niu L, et al. Comparison of expectations for health services between inpatients from mental health department and endocrinology department in China. Patient Prefer Adherence. 2019;13:1851-60. https:// doi.org/10.2147/PPA.S224071.

27. Departamento de Sanidad. Gobierno de Aragón. Plan de salud mental 2017-2021. Available at: https://www.aragon.es/-/estrategia-de-salud-mental. Accessed 12 Dec 2021

28. Ballesteros Pérez AM, García González AL, Fontcuberta Martínez J, Sánchez Rodríguez F, Pérez-Crespo C, Alcázar MF. La demora en la consulta de atención primaria: 'se puede mejorar? [time spent waiting at primary care clinics: can this be improved?]. Aten Primaria. 2003;31(6):377-81Spanish. https:// doi.org/10.1016/S0212-6567(03)70702-1.

\section{Publisher's Note}

Springer Nature remains neutral with regard to jurisdictional claims in published maps and institutional affiliations. 